This provisional PDF corresponds to the article as it appeared upon acceptance. A copyedited and fully formatted version will be made available soon.

\title{
Predicting playing status in professional water polo players: analysis by gender
}

Maria Helena VILA, Carmen MANCHADO, Josè A. ABRALDES, Carmen FERRAGUT

The Journal of Sports Medicine and Physical Fitness 2017 May 30

DOI: 10.23736/S0022-4707.17.07201-2

Article type: Original Article

(C) 2017 EDIZIONI MINERVA MEDICA

Subscription: Information about subscribing to Minerva Medica journals is online at:

http://www.minervamedica.it/en/how-to-order-journals.php

Reprints and permissions: For information about reprints and permissions send an email to:

journals.dept@minervamedica.it - journals2.dept@minervamedica.it - journals6.dept@minervamedica.it 


\title{
Predicting playing status in professional water polo players: analysis by gender
}

\author{
María Helena Vila ${ }^{*}$; Carmen Manchado ${ }^{2}$; José Arturo Abraldes ${ }^{3}$; Carmen Ferragut ${ }^{4}$ \\ 1 Faculty of Education and Sport Science, University of Vigo, Pontevedra, Spain. \\ 2 Faculty of Education, University of Alicante, Comunidad Valenciana, Spain. \\ 3 Faculty of Sport Sciences, University of Murcia, Murcia, Spain. \\ 4 Faculty of Medicine, University of Alcalá, Alcalá de Henares, Spain.
}

Brief running head: Predicting playing status in professional water polo players

\section{Correspondence to:}

Helena Vila. Faculty of Education and Sport Science. Campus A Xunqueira s/n, 36005 Pontevedra. Phone: 0034 986802056. Fax: 0034 986801701. E-mail: evila@uvigo.es

\section{Funding}

The authors would like to acknowledge funding support from Spanish Government grant (DEP 2008-06114), as well as to the Spanish water polo team for their support during the evaluations. 


\section{Abstract}

Background: The aim of this study was twofold: firstly, to identify the characteristics of water polo players that discriminate between women and men based on specific playing positions; and secondly to develop a predicting model to identify the characteristics that are best suited to a given playing position based on gender.

Methods: 130 professional water polo players were studied. Anthropometric characteristics and throwing velocity were analyzed in different situations: no defender or goalkeeper, goalkeeper only and the players made three rapid arm movements and then threw the ball at maximum speed without further feinting with goalkeeper. Measured variables were compared according to gender and player position using discriminant analysis.

Results: The predictive model accurately classifies $71.1 \%$ of the male players using three variables (arm span, muscle mass Lee and penalty without goalkeeper), and $64.7 \%$ of the female players using three variables (triceps skinfold, biceps skinfold and anteroposterior chest breadth).

Conclusions: The anthropometric characteristics and throwing velocity play an important role in identifying the different specific positions in male and female water polo players. In female players, the variables that were determinant in the predictive model, were those associated with body composition.

Key words: Discriminant analysis-Team sports-Women-Goalkeeper-Field player. 


\section{Introduction}

Different studies in water polo have confirmed that, anthropometric characteristics, body composition and throwing velocity play an important role in attaining a high level of achievement ${ }^{(1,2)}$. Recent research points out the importance of the specific physical fitness profile of different playing positions already recognized in team sports ${ }^{(3,4)}$ including water polo ${ }^{(5,6)}$. This line of investigation allows for advances to be made in the process of detecting sport talent, and improve the design of strength training ${ }^{(7)}$.

Studies in male water polo players identify differences between specific positions, wings and centers ${ }^{(1,6,8)}$. A literature review has shown that research studies on the female water polo players' profiles are quite limited and inconclusive $\mathrm{e}^{(9,10)}$. Thus, it is evident that additional information on anthropometric and physiological characteristics of elite water polo players is required ${ }^{(11)}$ and reports that comparing the differences between genders can help in order to direct the specific training requirements as well as obtaining a better understanding of the effect that other aspects of the game has for each gender.

Discriminating analysis is a classification technique that allows for the assignment and classification of new individuals based on value knowledge of certain discriminant variables detected within previously recognised groups, such as specific playing positions in team sports. Whilst in common practice this is a form of identifying talent within single discipline sports $^{(12,13)}$, predictive modelling seems to be scarcely used within multi-faceted team sports; perhaps due to the complexity of the games' skill requirements ${ }^{(14)}$.

Very limited information exists regarding the anthropometric characteristics and throwing velocity by playing position in water polo players. On the basis of discrimination analysis' characteristics and knowing the specific positions of water polo, the aim of this investigation is twofold: to identify characteristics that determine playing positions in water 
polo players based on gender; and the development of a predictive model that identifies the characteristics that best predicts the playing position by gender.

\section{Materials and methods}

\section{Experimental Approach to the Problem}

A casual comparative design (ex post facto design) was used to determine if anthropometric characteristics (height, body mass, skinfolds, limbs and skeletal breadth) and physical performance (throwing velocity), discriminate between playing positions of professional water polo players from both genders. Independent variables were gender and specific playing position. By having a sample of elite athletes, a discriminant analysis was performed by specific playing positions and gender, in order to assess the differences between anthropometric characteristics and physical performance in the same sport modality for men and woman.

All assessments were completed in the same month, during the in-season training period.

Subjects

A total of 84 elite male water polo players $(24.60 \pm 5.09$ years; $14.12 \pm 5.05$ playing experience) and 46 elite female water polo players ( $22.50 \pm 4.46$ years; $8.35 \pm 3.78$ playing experience) participated in this study. All of them were playing in the top Spanish professional water polo league. The sample was divided according to the specific playing position in wings, centers and goalkeepers.

The study was approved by the XXXXXXX University Committee on research involving human subjects and carried out according to the Declaration of Helsinki. All participants received verbal and written information about the study and gave written informed consent before the anthropometric and conditional assessment was carried out. 
Additional background information including date of birth, specific position and number of years of water polo playing was provided by each player.

\section{$\underline{\text { Anthropometrics }}$}

The International Society for the Advancement of Kinanthropometry (ISAK) ${ }^{(15)}$ guidelines were used to determine the anthropometric profile of water polo players. The subjects were measured in their club setting during a single measurement session. Unilateral measurements were taken on the right side of the body. Participants wore light clothing (slip) but no shoes.

Physical characteristics were measured in the following order: height, body mass, arm span, skinfolds, body girth and skeletal breadth. The anthropometric program included approximately 29 measurements. Height and weight measurements were made on a levelled platform scale (Seca, Barcelona, Spain) with an accuracy of $0.01 \mathrm{~kg}$ and $0.001 \mathrm{~m}$, respectively. Eight skinfolds (triceps, subscapularis, biceps, abdominal, iliac crest, suprailiac, front thigh and medial calf) were measured using the Holtain Skinfold Calliper with 10 g.mm $\mathrm{m}^{-2}$ of constant pressure. Eight limb and trunk girth (arm relaxed, arm flexed and tensed, forearm, waist, gluteal, thigh, calf and ankle) were measured using a Lufkin metal tape (Lufkin Executive Thinline, W606PM, USA) and six skeletal breadth (biacromial, biepicondylar-humerus, biepicondylar, biliocristal, anteroposterior chest and bitrochanteric) were measured using an anthropometer (GPM, Switzerland) with an accuracy of $0.01 \mathrm{~cm}$. Four lengths were measured using an anthropometer (GPM, Switzerland) with an accuracy of $0.01 \mathrm{~cm}$ in upper limbs (upper limb length, forearm length, hand length and hand width).

The body mass index (BMI) was calculated as weight $(\mathrm{kg})$ divided by height ${ }^{2}(\mathrm{~m})$. The fat free mass (FFM) $(\mathrm{Kg})$ was calculated using the method described by Lee ${ }^{(16)}$. 


\section{Throwing velocity}

Throwing velocity was assessed with a radar gun (StalkerPro Inc., Plano), with 100 $\mathrm{Hz}$ frequency of record and with sensibility $0.045 \mathrm{~m} \cdot \mathrm{s}^{-1}$, placed behind the goal post and positioned perpendicularly to the player. This test has shown to have very good test-retest reliability ${ }^{(6)}$. The players were invited to perform six shots under three different conditions (two shots in each condition) from the $5 \mathrm{~m}$-penalty line in the centers of the water polo goal. The three conditions included: no defender or goalkeeper, goalkeeper only and the players made three rapid arm movements and then threw the ball at maximum speed without further feinting with goalkeeper.

Prior to the throwing velocity assessment, subjects performed a 10-minute standardized warm up focused on specific aspects of throwing ability. Three series of two maximal intensity shoots were performed with 3 minutes' rest interval between sets and 30 seconds pause between two throws of the same set, using one hand and their own technique with a standard water polo ball (Mikasa 6000). In each serie of two shoots, players were immediately informed of the accomplished results, being only the best trial chosen for data analyses.

\section{Statistical analyses}

Statistical analyses were performed using SPSS package (15.0 version; SPSS, Inc., Chicago, IL, USA). Probability distribution of the variables of study was analyzed by the calculation of basic descriptive statistics (mean and standard deviation). The assumption of homogeneity of the variance was tested using Levene's test and the assumption of normality was checked using Kolgomorov-Smirnov test and Lilliefors test. A linear discriminant analysis was also conducted on the two groups in order to obtain a regression equation that could be used to predict playing positions on the basis of the dependent variables. All dependent variables were analysed together in order to determine which combination of measures best 
discriminated between playing positions. Wilk's Lambda criterion was used to determine whether a variable entered the model. A stepwise selection method included initially the variable that most minimized the value of Wilk's Lambda, but this variable was only selected if satisfy the entry criterion $(\mathrm{F}=3.84)$. Then, a pairwise combination of the variable included in the first step with one of them was made, but this new variable must satisfy the entry criterion. Whenever a new variable was incorporated to the model, previous selected variables were re-evaluated in order to determine if they satisfy or not the exit criterion $(F=2.71)$. If any of the variables already selected satisfy the exit criterion it was removed from the model. Wilk's Lambda canonical correlation index, that allows evaluating the information provided by the discriminant function and percentage of subjects correctly classified for each playing position in male and female players, were computed as indicators of performance predictive capacity. An alpha of 0.05 was adopted for all tests of significance.

\section{Results}

The predictive model accurately classifies $71.1 \%$ of the male players using three variables (arm span, muscle mass by Lee and throwing velocity (speed) in penalty without goalkeeper situation) (Table 1). Moreover, if we analyse our results by specific playing positions in male players, we found that our model accurately classifies $84.6 \%$ of the wing players, $62.1 \%$ of the centers players and $37.5 \%$ of the Goalkeepers, using the aforementioned variables.

Nevertheless, our predictive model accurately classifies $64.7 \%$ of the female water polo players using three anthropometric variables (triceps skinfold, biceps skinfold and anteroposterior chest breadth). We have to notice that in female model only entered anthropometric variables and two of them are related with fat mass in upper limbs. 
If we analyse the female results by specific playing positions, we found that our model show an accuracy of $47 \%$ for wings, $92.3 \%$ for centers and $50 \%$ for goalkeepers using those variables. (Table 1).

\section{[INSERT TABLE 1]}

The following regressions equations were derived for classifying athletes into playing position groups.

Equations 1 show the discriminant analysis equations that were developed for males in order to their different specific playing positions (1.1. for wings, 1.2 for centers and 1.3 for Goalkeepers).

1. Discriminant analysis to predict selection of male water polo players:

$$
\text { 1.1. Wing }=-514.88+(4.329 * \text { arm Span })+(-1.070 * \text { muscle mass Lee })+(3.091 *
$$
penalty without goalkeeper)

1.2. Centers $=-539.161+(4.462 *$ arm Span $)+(-0.886 *$ muscle mass Lee $)+(2.975 *$ penalty without goalkeeper)

$$
\text { 1.3. Goalkeeper }=-481.891+(4.363 * \text { arm Span })+(-1.421 * \text { muscle mass Lee })
$$

$+(2.682 *$ penalty without goalkeeper $)$

Equations 2 show the discriminant analysis equations that were developed for females in order to their different specific playing positions (2.1. for wings, 2.2 for centers and 2.3 for Goalkeepers).

2. Discriminant analysis to predict selection of female water polo players: 
2.1. Wing $=-189.689+(2.263 *$ triceps skinfold $)+(-9.809 *$ biceps skinfold $)+$ (21.656* anteroposterior chest breadth)

2.2. Centers $=-211.227+(3.203 *$ triceps skinfold $)+(-11.526 *$ biceps skinfold $)+$ $(22.633 *$ anteroposterior chest breadth)

2.3. Goalkeeper $=-580.457+(4.682 *$ triceps skinfold $)+(-18.667 *$ biceps skinfold $)+$ (37.859* anteroposterior chest breadth)

\section{Discussion}

This is the first study that makes a discriminant analysis based on specific positions of elite water polo players. The results show the importance of arm span, muscle percentage and throwing velocity in determining the different positions of male water polo players, especially for attackers and defenders. Those aspects are related with training status. In what refers to female players, body composition explains the difference between specific positions. The results suggest that aspects related with "fat mass" shows a difference for female players and none of the variables related with strength entered in the equations.

In male players, the three variables contemplated in the model allow to correctly classify $84.6 \%$ of attackers and $62.1 \%$ of defenders. The anthropometric characteristics given by the scientific literature as important to reach a high level of performance in water polo (height, weight, arm span) confirm the importance of arm span as the variable that discriminates among positions. It is a variable that provides advantages to the play of one versus one (blocking the ball, defense, capacity of ball reception) and for throwing speed ${ }^{(6)}$. Muscle mass is an important characteristic for the performance in water polo, both in attack and defense (wrestling to win and maintain a position, capacity of elevation on the water) ${ }^{(17}$, 18). The maximum throwing speed (without a goalkeeper) is confirmed as a determinant fact for attacking play ${ }^{(18-20)}$. 
The above variables (muscle percentage and throwing velocity) can be modified through training, which is an important fact, since the training load design is determined by the coach. These results indicate a specialization in male play, and are in line with the results obtained in research carried out by Escalante et al. ${ }^{(21)}$.

Different authors state the importance of body fat as a positive fact in water polo due to its relation with players' floating ${ }^{(17,22)}$, the results of this study in male players are not in line with such researches. Facts related with strength seem to be the variables that discriminate among specific field positions (wing and centers), maybe due to the fact that there are a very high specialization in male water polo players at this level, so high levels of strength are required, but muscle mass is not necessary in the same way for each specific playing position, while buoyancy is required equally in all the specific playing positions, therefore all players present optimal body fat levels and it is not a factor that discriminate among positions.

Results in female players set out that bicipital and tricipital folds and chest anteroposterior breadth are the variables that discriminate and allow for the accurate classification of $47.1 \%$ of the attackers, $92.3 \%$ of the defenders and $50 \%$ of the goalkeepers. The variables making up the equation belong to body composition and anthropometric characteristics. These results are in line with other studies ${ }^{(9,22)}$, where body fat is positively related with the floating ability, a fact that has a positive influence in some of the motor manifestations in water. Moreover, considering that $69 \%$ of the total play time, the players carry out static activities (not swimming), and that the defenders are most of that time in fighting situations ${ }^{(9)}$, these data reinforce the importance of the folds and lung capacity for the specific position of defender ${ }^{(1,5)}$. Folds may be modified through training, but do not confirm the role that training plays in the selection of the specific position. The analysis results reinforce the idea defended by Escalante et al. ${ }^{(21)}$ : the meagre specialization existing 
in female water polo due to the low number of participants makes selection limited and also could be reinforce the idea that female water polo players show low levels of strength as expressed by Platanou and Varamenti ${ }^{(23)}$ and Martinez et $\mathrm{al}^{(10)}$. The data presented indicate that the specialization in female water polo requires more attention. These results indicate the need to continue in this line of study to reach conclusions that could be extrapolated to male and female water polo players.

In male players, the correct percentage of classification is $71.1 \%$ for the entire sample and $84.6 \%$ for the best classification. In female players, it is $64.7 \%$ for the entire sample and $92.3 \%$ for the best classification. These results lead to the contemplation of aspects not evaluated in this study (technical, tactical, psychological) ${ }^{(24,25)}$, for specific positions with lower correct classification percentages (mainly goalkeepers of both sexes and attacker female players). These results cannot be compared with other research carried out in water polo. Studies carried out for specific positions in other collective sports present lower correct classification values; in male handball ${ }^{(26)}$, similar to football players ${ }^{(27)}$, and rugby ${ }^{(28)}$. In female players the results are similar to the study presented by Carter et al. ${ }^{(29)}$ in basketball, and by Katic et al. ${ }^{(30)}$ in handball, but lower. than that obtained by Carbajal et al. ${ }^{(31)}$ for female volleyball players.

\section{Conclusions}

Summarising the findings of the present study,1) in male players it has been confirmed that throwing velocity and muscle percentage are important discriminant factors for a specific position; 2) adipose tissue is important in female players for the specific position of central (defenders); it has been associated to the ability to fight and to win the position; 3 ) the discriminant capacity of the variables analysed in this study reveal that for the specific position of goalkeeper differences must be sought in other aspects not evaluated in this 
research, and 4) the variables with more relevance in the model have been those related to body composition. It was concluded that body composition is important for elite water polo players of both genders.

Coaches can use this information to continue insisting on the importance of strength training in male for specific playing positions.

In the case of the women, coaches should increase the training load, mainly strength training to alleviate this lack of force that seem to present female water polo players in order to be able to get higher specialization by specific playing position. 


\section{References}

1. D'Auria S, Gabbett T. A time-motion analysis of international women's water polo match play. Int J Sports Physiol Perform. 2008;3(3):305-19.

2. Stevens HB, Brown LE, Coburn JW, Spiering BA. Effect of swim sprints on throwing accuracy and velocity in female collegiate water polo players. J Strength Cond Res. 2010;24(5):1195-8.

3. Gabbett TJ, Seibold AJ. Relationship between tests of physical qualities, team selection, and physical match performance in semiprofessional rugby league players. $\mathrm{J}$ Strength Cond Res. 2013;27(12):3259-65.

4. Matthys SP, Fransen J, Vaeyens R, Lenoir M, Philippaerts R. Differences in biological maturation, anthropometry and physical performance between playing positions in youth team handball. J Sports Sci. 2013;31(12):1344-52.

5. Tan F, Polglaze T, Dawson B. Activity profiles and physical demands of elite women's water polo match play. J Sports Sci. 2009;27(10):1095-104.

6. Ferragut C, Abraldes JA, Vila H, Rodriguez N, Argudo FM, Fernandes R. Anthropometry and throwing velocity in elite water polo by specific playing positions. $\mathrm{J}$ Hum Kinet. 2011;27:31-44.

7. Kondric M, Uljevic O, Gabrilo G, Kontic D, Sekulic D. General anthropometric and specific physical fitness profile of high-level junior water polo players. J Hum Kinet. 2012;32:157-65.

8. Bloomfield J, Blanksby BA, Ackland TR, Allison GT. The influence of strength training on overhead throwing velocity of elite water polo players. Australian Journal of Science and Medicine in Sport. 1990;22(3):63-9.

9. Tan FH, Polglaze T, Dawson B, Cox G. Anthropometric and fitness characteristics of elite Australian female water polo players. J Strength Cond Res. 2009;23(5):1530-6. 
10. Martinez JG, Vila MH, Ferragut C, Noguera MM, Abraldes JA, Rodriguez N, et al. Position-specific anthropometry and throwing velocity of elite female water polo players. J Strength Cond Res. 2015;29(2):472-7.

11. Clarke AC, Anson JM, Pyne DB. Game movement demands and physical profiles of junior, senior and elite male and female rugby sevens players. J Sports Sci. 2016:1-7.

12. Mikulic P, Ruzic L. Predicting the $1000 \mathrm{~m}$ rowing ergometer performance in 12-13year-old rowers: the basis for selection process? J Sci Med Sport. 2008;11(2):218-26.

13. Saavedra JM, Escalante Y, Rodriguez FA. A multivariate analysis of performance in young swimmers. Pediatr Exerc Sci. 2010;22(1):135-51.

14. Woods CT, Raynor AJ, Bruce L, McDonald Z, Collier N. Predicting playing status in junior Australian Football using physical and anthropometric parameters. J Sci Med Sport. 2015;18(2):225-9.

15. Stewart A, Marfell-Jones M, Olds T, Ridder H. International Standards for anthropometric assessment. Lower Hutt, New Zealand: International Society for the Advancement of Kinanthropometry (ISAK); 2011.

16. Lee RC, Wang Z, Heo M, Ross R, Janssen I, Heymsfield SB. Total-body skeletal muscle mass: development and cross-validation of anthropometric prediction models. Am J Clin Nutr. 2000;72(3):796-803.

17. Platanou T. On-water and dryland vertical jump in water polo players. J Sports Med Phys Fitness. 2005;45(1):26-31.

18. Smith HK. Applied physiology of water polo. Sports Med. 1998;26(5):317-34

19. Van der Wende K. The effects of game-specific task constraints on the outcome of the water polo shot. New Zealand: Auckland University of Technology; 2005. 
20. Alcaraz PE, Abraldes JA, Ferragut C, Rodriguez N, Argudo FM, Vila H. Throwing velocities, anthropometric characteristics, and efficacy indices of women's European water polo subchampions. J Strength Cond Res. 2011;25(11):3051-8.

21. Escalante Y, Saavedra JM, Mansilla M, Tella V. Discriminatory power of water polo game-related statistics at the 2008 Olympic Games. J Sports Sci. 2011;29(3):291-8.

22. Peric M, Zenic N, Mandic GF, Sekulic D, Sajber D. The reliability, validity and applicability of two sport-specific power tests in synchronized swimming. J Hum Kinet. 2012;32:135-45.

23. Platanou T, Varamenti E. Relationships between anthropometric and physiological characteristics with throwing velocity and on water jump of female water polo players. $\mathrm{J}$ Sports Med Phys Fitness. 2011;51(2):185-93.

24. Elferink-Gemser MT, Visscher C, Lemmink KA, Mulder TW. Relation between multidimensional performance characteristics and level of performance in talented youth field hockey players. J Sports Sci. 2004;22(11-12):1053-63.

25. Lidor R, Falk B, Arnon M, Cohen Y, Segal G, Lander Y. Measurement of talent in team handball: the questionable use of motor and physical tests. J Strength Cond Res. 2005;19(2):318-25.

26. Massuça L, Fragoso I. Study of Portuguese handball players of different playing status. A morphological and biosocial perspective. Biol Sport. 2011;28(1):37-44.

27. Sutton L, Scott M, Wallace J, Reilly T. Body composition of English Premier League soccer players: influence of playing position, international status, and ethnicity. J Sports Sci. 2009;27(10):1019-26.

28. Carlson BR, Carter JE, Patterson P, Petti K, Orfanos SM, Noffal GJ. Physique and motor performance characteristics of US national rugby players. J Sports Sci. 1994;12(4):403-12. 
29. Carter JE, Ackland TR, Kerr DA, Stapff A. Somatotype and size of elite female basketball players. J Sports Sci. 2005;23(10):1057-63.

30. Katic R, Cavala M, Srhoj V. Biomotor structures in elite female handball players. Coll Antropol. 2007;31(3):795-801.

31. Carbajal L, del-Castillo-Negrete D, Martinell JJ. Dynamics and transport in meanfield coupled, many degrees-of-freedom, area-preserving nontwist maps. Chaos. 2012;22(1):013137. 
Funding. - The authors would like to acknowledge funding support from Spanish Government grant (DEP 2008-06114), as well as to the Spanish water polo team for their support during the evaluations. 


\section{TITLES OF TABLES}

Table I - Discriminant analysis model for different types of gender and playing positions, giving the percentage correctly classified, Wilks' $\chi$, canonical correlation index, and variables included in the model by order of selection. 
Table 1 Discriminant analysis model for different types of gender and playing positions, giving the percentage correctly classified, Wilks' $\chi$, canonical correlation index, and variables included in the model by order of selection.

\section{All discriminant functions and variables included}

Men's

0.804

14.805

$<0.001$

0.442

71.1

84.6

62.1

37.5

\section{Women's}

0.497

8.380

$<0.015$

0.709

64.7

47.1

Centre correctly classified (\%)

Goalkeeper correctly classified (\%)
92.3

50

\section{Variables entered}

Arm Span

Muscle Mass Lee

Penalty without

goalkeeper
Triceps skinfold

Biceps skinfold

Anteroposterior chest

breadth 